\title{
VIBRATION ATTENUATION MECHANISM OF THE ROTOR SYSTEM WITH ANISOTROPIC SUPPORT STIFFNESS
}

\begin{abstract}
Summary
Using the one-dimensional finite element method, the dynamic behaviour of a doubledisk rotor system with anisotropic supports is studied in this paper. First, the natural frequencies, whirl state and unbalance response of the rotor system are analysed. Then, the vibration attenuation mechanism of the rotor system under the effect of bearing damping and accelerating rotor is discussed in detail. The research results show that stiffness anisotropy makes natural frequency lines of the rotor system tend to diverge from each other. The damping in bearings not only decreases the amplitude of forward and backward whirls but also reduces the spin speed range of backward whirl. The whirl orbit of the rotor system approximates a straight line at the spin speeds near the critical point of the backward and forward whirls. For the unbalance response of the rotor system with anisotropic supports, the forward natural frequency dominates in the direction of the strong stiffness axis, while the unbalance response in the direction of the weak stiffness axis is mainly affected by the backward natural frequency. Increasing the run-up acceleration can decrease the amplitude of backward and forward whirls, but it cannot reduce the spin speed range of backward whirl.
\end{abstract}

Key words: $\quad$ rotor system, anisotropic supports, vibration attenuation mechanism, bearing damping, accelerating rotor

\section{Introduction}

The rotor system is a core component of rotating machinery. The design of robust rotor dynamics can significantly improve the working efficiency of rotating machinery and reduce unit vibration levels $[1,2]$. Currently, rotating machinery requires higher speeds and tighter clearances due to increased thermal efficiency and power demand. In this situation, the rotor system may experience an unacceptable vibration level that can cause excessive wear of bearings and blades of the rotor, which can result in a possibility of the rotor coming into contact with the stationary housing [3, 4].

Anisotropy occurs when support stiffness is not the same in radial directions [5]. The support stiffness of the rotor system during operation always shows anisotropy after some time [6]. Anisotropic stiffness usually makes the rotor system whirl in elliptical orbits and contributes to the appearance of additional backward critical speeds [7, 8]. Genta et al. [9] 
numerically proved that the transient-state unbalance response related to the accelerating rotor showed very strong oscillations and a frequency of close to twice the spin frequency of the rotor system with anisotropic support stiffness. Lee et al. [10] explained that the compression and tension sides of the rotating shaft undergo two reversals in stress per revolution during the backward whirl. Joh et al. [11] identified experimentally the backward whirl and the strength of stiffness anisotropy by a complex modal testing technique. Semenov et al. [12, 13] validated a new accelerometer sensor mounting scheme to detect $1 \mathrm{X}$ splitting resonance caused by anisotropic supports. The sensor is placed at a 45-degree angle to the weak and strong stiffness axes and only one accelerometer sensor is required to identify the effects caused by anisotropic supports in a real aircraft engine. Zhang et al. [14] proposed an improved holospectrum-based balancing method that balances the rotor system with stiffness anisotropy more effectively than conventional balancing methods.

The literature quoted above is about the identification and analysis of some special dynamic phenomena of the rotor system with anisotropic supports. In engineering, two common methods used for minimizing the adverse effects of anisotropic supports are: increasing the bearing damping and accelerating the rotor through critical speeds. However, the effects of bearing damping and rotor acceleration on the dynamic behaviour of this type of rotor system have not been clearly illustrated. In what follows, Section 2 illustrates the onedimensional finite element method used for the dynamic modelling of the rotor system. The computational model of a double-disk rotor system is described in Section 3. In Section 4, the natural frequencies, whirl state and unbalance response of the rotor systems with isotropic and anisotropic supports are analysed for the purpose of comparison. Moreover, the vibration attenuation mechanism of the rotor system with anisotropic supports under the effect of bearing damping and accelerating rotor is discussed in detail. The main conclusions are summarized in Section 5.

\section{Finite element modelling of the rotor system}

\subsection{One-dimensional finite element model}

The Timoshenko beam element is adopted to consider the shear effect and rotary inertia of the relatively thick rotor shaft studied in this paper. Only the bending vibration of the rotor system is considered here and the finite element discretization of the rotor shaft is shown in Fig. 1. The four degrees of freedom of each node related to the bending vibration are considered.

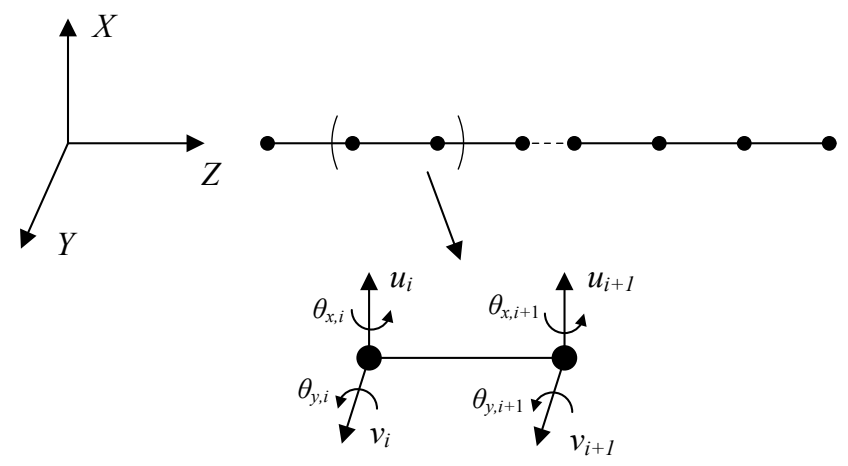

Fig. 1 Finite element discretization of the rotor shaft

The $Z$-axis in Fig. 1 is the rotation axis of the rotor system. The generalized coordinate vector of the $i$ th shaft segment is $\boldsymbol{q}_{i}=\left[\begin{array}{llllllll}u_{i} & v_{i} & \theta_{x, i} & \theta_{y, i} & u_{i+1} & v_{i+1} & \theta_{x, i+1} & \theta_{y, i+1}\end{array}\right]^{\mathrm{T}}$, where $\left(u_{i}, v_{i}\right)$ and $\left(\theta_{x, i}, \theta_{y, i}\right)$ are the lateral displacements and the rotation angles of the $i$ th node along the $x$ and $y$ axes, respectively. The directions of $\left(u_{i}, v_{i}\right)$ and $\left(\theta_{x, i}, \theta_{y, i}\right)$ shown in Fig. 1 are the positive 
directions of bending deformation. The local element matrices of the shaft segment are obtained from the Lagrange equation $[15,16]$ as expressed below:

$$
\frac{d}{d t}\left(\frac{\partial T}{\partial \dot{q}_{i}}\right)-\frac{\partial T}{\partial q_{i}}+\frac{\partial U}{\partial q_{i}}=Q_{i},
$$

where $T$ and $U$ are the kinetic energy and the strain energy of the $i$ th shaft segment and $Q_{i}$ is the generalized force acting on the shaft segment. The stiffness matrix, mass matrix and gyroscopic matrix of the shaft segment are obtained by inserting the strain energy and kinetic energy into the Lagrange equation, respectively. Assuming that the disk is rigid and ignoring its strain energy, the blade and the blade disk are equivalent to the centre of mass of the rigid disk in the form of mass and rotary inertia. The mass matrix and gyroscopic matrix of the rigid disk are obtained by inserting the kinetic energy of the rigid disk into the Lagrange equation. It is assumed that bearings have a linear load-deformation relationship and only the stiffness and damping coefficients in the radial directions are taken into account. The reaction forces of the bearing acting on the rotor are functions of the whirl displacements and whirl velocities of the rotor at the bearing [17], as shown below:

$$
\left[\begin{array}{l}
f_{x} \\
f_{y}
\end{array}\right]=-\left[\begin{array}{ll}
k_{x x} & k_{x y} \\
k_{y x} & k_{y y}
\end{array}\right]\left[\begin{array}{l}
x \\
y
\end{array}\right]-\left[\begin{array}{cc}
c_{x x} & c_{x y} \\
c_{y x} & c_{y y}
\end{array}\right]\left[\begin{array}{c}
\dot{x} \\
\dot{y}
\end{array}\right],
$$

where $f_{x}$ and $f_{y}$ are the reaction forces of the bearing acting on the rotor in the $x$ and $y$ directions, respectively; $k_{i j}$ and $c_{i j}$ are the stiffness and damping coefficients of the bearing; $\left(k_{x x}, k_{y y}\right)$ and $\left(c_{x x}, c_{y y}\right)$ are the direct stiffness and direct damping coefficients, and $\left(k_{x y}, k_{y x}\right)$ and $\left(c_{x y}, c_{y x}\right)$ are the cross-coupled stiffness and cross-coupled damping coefficients. The global dynamic matrices of the rotor system are obtained by assembling the local element matrices of the shaft segments, bearings and rigid disks according to their axial position on the rotor.

\subsection{Steady-state unbalance response of the rotor system}

The dynamic differential equation of the rotor system is [18]

$$
\boldsymbol{M} \ddot{\boldsymbol{q}}+(\boldsymbol{C}+\Omega \boldsymbol{G}) \dot{\boldsymbol{q}}+\boldsymbol{K} \boldsymbol{q}=\boldsymbol{Q},
$$

where $\boldsymbol{M}$ is the mass matrix, $\boldsymbol{C}$ the damping matrix, $\boldsymbol{K}$ the stiffness matrix, $\boldsymbol{G}$ the gyroscopic matrix, $\boldsymbol{q}$ the displacement column vector, $\dot{\boldsymbol{q}}$ the velocity column vector, $\ddot{\boldsymbol{q}}$ the acceleration column vector, $\Omega$ the rotor spin speed, and $\boldsymbol{Q}$ the external excitation force column vector. To solve the second-order differential equation of Eq. (3), it is often transformed into a first-order differential equation in the form of state space [19]

$$
\frac{d}{d t}\left[\begin{array}{c}
\boldsymbol{q} \\
\dot{\boldsymbol{q}}
\end{array}\right]=\left[\begin{array}{cc}
\mathbf{0} & \mathbf{I} \\
-\boldsymbol{M}^{-1} \boldsymbol{K} & -\boldsymbol{M}^{-1}(\Omega \boldsymbol{G}+\boldsymbol{C})
\end{array}\right]\left[\begin{array}{l}
\boldsymbol{q} \\
\dot{\boldsymbol{q}}
\end{array}\right]+\left[\begin{array}{c}
\mathbf{0} \\
\boldsymbol{M}^{-1} \boldsymbol{Q}
\end{array}\right] .
$$

If a rotor system is discretized into $N$ nodes, the rotor system has $4 N$ degrees of freedom. $\boldsymbol{M}, \boldsymbol{K}, \boldsymbol{C}$, and $\boldsymbol{G}$ are the $4 N$ dimensional square matrices, $\mathbf{0}$ and $\mathbf{I}$ are the $4 N$ dimensional zero and unit matrices, and $\boldsymbol{q}, \dot{\boldsymbol{q}}, \ddot{\boldsymbol{q}}$ and $\boldsymbol{Q}$ are the $4 N \times 1$ dimensional column vectors. If there is an unbalance mass on the $k$ th node where the disk is located, the components of the unbalance excitation force $\boldsymbol{Q}_{\boldsymbol{k}}$ at $4 k-3,4 k-2,4 k-1$, and $4 k$ degrees of freedom are

$$
\begin{aligned}
& \boldsymbol{Q}_{\boldsymbol{k}}=\left[\begin{array}{llll}
m \Omega^{2} \cos (\Omega t+\delta) & m \Omega^{2} \sin (\Omega t+\delta) & 0 & 0
\end{array}\right]^{\mathrm{T}} \\
& =\operatorname{Re}\left(\left[\begin{array}{llll}
m \sigma \Omega^{2} e^{j \delta} e^{j \Omega t} & -j m \sigma \Omega^{2} e^{j \delta} e^{j \Omega t} & 0 & 0
\end{array}\right]^{\mathrm{T}}\right), \\
& =\operatorname{Re}\left(\Omega^{2} e^{j \Omega t}\left[\begin{array}{llll}
m \varepsilon e^{j \delta} & -j m \varepsilon e^{j \delta} & 0 & 0
\end{array}\right]^{\mathrm{T}}\right) \\
& =\operatorname{Re}\left(\Omega^{2} e^{j \Omega t} \boldsymbol{b}_{\mathbf{0}}\right)
\end{aligned}
$$


where $m$ is the unbalance mass, $\varepsilon$ is the eccentricity, $\delta$ is the phase of unbalance mass relative to the positive $X$-axis, and Re represents the taking of the real part of a complex number. Assuming that the steady-state unbalance response of the rotor system under the effect of unbalance force is $\boldsymbol{q}=\operatorname{Re}\left(\boldsymbol{q}_{0} \mathrm{e}^{j \Omega t}\right)$, and inserting $\boldsymbol{q}$ and $\boldsymbol{Q}_{\boldsymbol{k}}$ into Eq. (3), one obtains

$$
\boldsymbol{q}_{\mathbf{0}}=\left[\left(\boldsymbol{K}-\Omega^{2} \boldsymbol{M}\right)+j \Omega(\Omega \boldsymbol{G}+\boldsymbol{C})\right]^{-1} \Omega^{2} \boldsymbol{b}_{\mathbf{0}},
$$

where $\boldsymbol{q}_{0}$ is a complex number whose expression is assumed to be

$$
\boldsymbol{q}_{\mathbf{0}}=a+b j=\left|\boldsymbol{q}_{\mathbf{0}}\right| e^{j \alpha},
$$

where $\left|\boldsymbol{q}_{\mathbf{0}}\right|=\sqrt{a^{2}+b^{2}}, \alpha=\arctan (b / a)$. Therefore, the steady-state unbalance response $\boldsymbol{q}$ of the rotor system is

$$
\boldsymbol{q}=\operatorname{Re}\left(\left|\boldsymbol{q}_{\mathbf{0}}\right| e^{j(\Omega t+\alpha)}\right)=\left|\boldsymbol{q}_{\mathbf{0}}\right| \cos (\Omega t+\alpha) .
$$

It can be seen from Eq. (8) that the modulus and the phase angle of the complex number $\boldsymbol{q}_{\mathbf{0}}$ are the amplitude and the phase of unbalance response of the rotor system, respectively. The whirl direction of a node on the rotor system depends on the difference between the phase $\alpha_{y}$ in the $y$-direction and the phase $\alpha_{x}$ in the $x$-direction. If $\left(\alpha_{y}-\alpha_{x}\right) \pm 2 n \pi=0$ or $\pi$, then the whirl orbit of the node is a straight line; if $0<\left(\alpha_{y}-\alpha_{x}\right) \pm 2 n \pi<\pi$, then the node shows a forward-whirl orbit; if $-\pi<\left(\alpha_{y}-\alpha_{x}\right) \pm 2 n \pi<0$, then the node shows a backward-whirl orbit, where $n$ is an integer.

\subsection{Transient-state unbalance response of the rotor system}

Since the rotor spin speed is time-varying for the transient-state analysis, the unbalance excitation force $\boldsymbol{Q}_{\boldsymbol{k}}$ in Eq. (5) is rewritten as [14]

$$
\begin{aligned}
\boldsymbol{Q}_{\boldsymbol{k}} & =\left[\begin{array}{c}
m \varepsilon \dot{\phi}(t)^{2} \cos [\phi(t)+\delta]+m \varepsilon \ddot{\phi}(t) \sin [\phi(t)+\delta] \\
m \varepsilon \dot{\phi}(t)^{2} \sin [\phi(t)+\delta]-m \varepsilon \ddot{\phi}(t) \cos [\phi(t)+\delta] \\
0 \\
0
\end{array}\right], \\
& =\operatorname{Re}\left[\begin{array}{c}
m \varepsilon\left[\dot{\phi}(t)^{2}-j \ddot{\phi}(t)\right] e^{j[\phi(t)+\delta]} \\
m \varepsilon\left\{-j\left[\dot{\phi}(t)^{2}-j \ddot{\phi}(t)\right] e^{j[\phi(t)+\delta]}\right\} \\
0 \\
0
\end{array}\right]
\end{aligned}
$$

where $\phi(t), \dot{\phi}(t)$, and $\ddot{\phi}(t)$ denote the spin angle, spin speed, and run-up acceleration at time $t$, respectively. The fourth-order Runge-Kutta integration method is adopted to obtain the transient-state unbalance response of the rotor system. According to the sampling theorem, the sampling frequency should be greater than 2 times the highest natural frequency of the rotor system. In addition, the time step for the transient-state integration calculation must be sufficiently small, which requires a significantly large amount of computational effort. An effective method is to use a model-reduction technique before performing the numerical integration. Since the unbalance response is only required at a lower spin speed of most of the rotating machinery in engineering, only the lower modes of the rotor system are retained in the model-reduction technique. The model-reduction technique has a double benefit: by 
retaining the first few modes of the rotor system, a larger time step can be used and fewer equations need to be solved.

The lower modes $\boldsymbol{T}_{\boldsymbol{r}}$ of the rotor system, neglecting the bearing damping and gyroscopic effects, can be obtained in terms of the mass matrix $\boldsymbol{M}$ and the stiffness matrix $\boldsymbol{K} . r$ is the number of retained modes and $\boldsymbol{T}_{\boldsymbol{r}}$ is the $4 N \times r$ dimensional matrix. The dynamic matrices of the rotor system are reduced to the following form

$$
\left\{\begin{array}{l}
\boldsymbol{M}_{\boldsymbol{r}}=\boldsymbol{T}_{\boldsymbol{r}}^{T} \boldsymbol{M} \boldsymbol{T}_{r} \\
\boldsymbol{K}_{\boldsymbol{r}}=\boldsymbol{T}_{\boldsymbol{r}}^{T} \boldsymbol{K} \boldsymbol{T}_{r} \\
\boldsymbol{C}_{\boldsymbol{r}}=\boldsymbol{T}_{\boldsymbol{r}}^{T} \boldsymbol{C} \boldsymbol{T}_{r} \\
\boldsymbol{G}_{\boldsymbol{r}}=\boldsymbol{T}_{\boldsymbol{r}}^{T} \boldsymbol{G} \boldsymbol{T}_{r} \\
\boldsymbol{Q}_{\boldsymbol{r}}=\boldsymbol{T}_{\boldsymbol{r}}^{T} \boldsymbol{Q}
\end{array}\right.
$$

In this case, Eq. (4) is rewritten as

$$
\frac{d}{d t}\left[\begin{array}{c}
\boldsymbol{q}_{\boldsymbol{r}} \\
\dot{\boldsymbol{q}}_{\boldsymbol{r}}
\end{array}\right]=\left[\begin{array}{cc}
\mathbf{0}_{\boldsymbol{r}} & \mathbf{I}_{\boldsymbol{r}} \\
-\boldsymbol{M}_{\boldsymbol{r}}^{-1} \boldsymbol{K}_{\boldsymbol{r}} & -\boldsymbol{M}_{\boldsymbol{r}}^{-1}\left(\Omega \boldsymbol{G}_{\boldsymbol{r}}+\boldsymbol{C}_{\boldsymbol{r}}\right)
\end{array}\right]\left[\begin{array}{c}
\boldsymbol{q}_{\boldsymbol{r}} \\
\dot{\boldsymbol{q}}_{\boldsymbol{r}}
\end{array}\right]+\left[\begin{array}{c}
\mathbf{0}_{\boldsymbol{r}} \\
\boldsymbol{M}_{\boldsymbol{r}}^{-1} \boldsymbol{Q}_{\boldsymbol{r}}
\end{array}\right],
$$

where $\boldsymbol{M}_{r}, \boldsymbol{K}_{\boldsymbol{r}}, \boldsymbol{C}_{\boldsymbol{r}}$, and $\boldsymbol{G}_{\boldsymbol{r}}$ are the $r$ dimensional square matrices, $\mathbf{0}_{\boldsymbol{r}}$ and $\mathbf{I}_{\boldsymbol{r}}$ are the $r$ dimensional zero and unit matrices, respectively, and $\boldsymbol{q}_{r}, \dot{\boldsymbol{q}}_{r}, \ddot{\boldsymbol{q}}_{r}$ and $\boldsymbol{Q}_{r}$ are the $r \times 1$ dimensional column vectors. The transient-state unbalance response $\boldsymbol{q}_{r}$ of the reduced rotor system is obtained by the numerical integration of Eq. (11). Then $\boldsymbol{q}_{r}$ is expanded by Eq. (12),

$$
q=T_{r} q_{r},
$$

to obtain the unbalance response of all degrees of freedom.

\section{A computational model of the rotor system}

The double-disk rotor system analysed in Ref. [19] is adopted as the research object in the paper. As shown in Fig. 2, the length of the shaft is $1.5 \mathrm{~m}$ and the shaft diameter is $50 \mathrm{~mm}$. The shaft is discretized into seven nodes and the distance between adjacent nodes is $0.25 \mathrm{~m}$. Relative to the left end bearing 1, the disk 1 and disk 2 are located at $0.5 \mathrm{~m}$ and $1 \mathrm{~m}$, respectively. Each disk is $70 \mathrm{~mm}$ thick and the diameter of disk 1 and disk 2 is 280 and $350 \mathrm{~mm}$, respectively. The shaft and disks are both made of steel with a modulus of elasticity of $E=211 \mathrm{GPa}$, a density of $\rho=7810 \mathrm{~kg} / \mathrm{m}^{3}$ and a Poison's ratio of $v=0.3$. For the purpose of comparison, the effects of both isotropic and anisotropic stiffness on dynamic characteristics of the rotor system are considered. The direct stiffness coefficient of the bearings in the $x$-direction and $y$-direction is $10^{6} \mathrm{~N} / \mathrm{m}$ for isotropic supports, while for anisotropic supports, the direct stiffness in the $x$-direction is $10^{6} \mathrm{~N} / \mathrm{m}$ and in the $y$-direction $8 \times 10^{5} \mathrm{~N} / \mathrm{m}$.

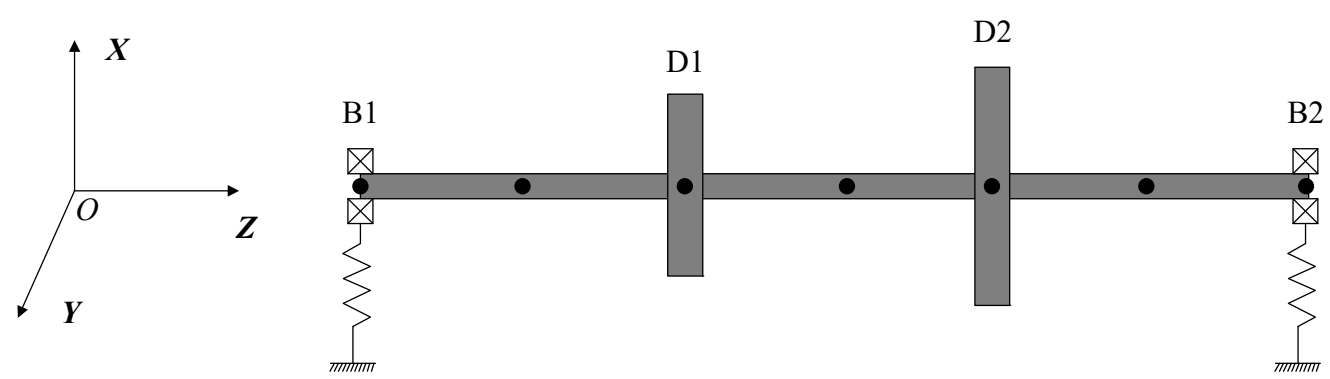

Fig. 2 A double-disk rotor system 


\section{Computation results}

\subsection{Natural frequency of the rotor system}

The eigenvalues of the state-space matrix in Eq. (4) are calculated at different spin speeds; the absolute value of the imaginary part of the eigenvalues are natural frequencies of the rotor system. The Campbell diagram of the rotor system is obtained by drawing the relationship between natural frequencies and the spin speeds. The Campbell diagram of the double-disk rotor system with the isotropic and the anisotropic stiffness is shown in Fig. 3. The dashed line is the $1 \mathrm{X}$ spin frequency line. FW and BW indicate the natural frequency lines of the forward and the backward whirl, respectively. The intersections of the spin frequency line and the natural frequency lines are defined as the critical speeds of the rotor system.

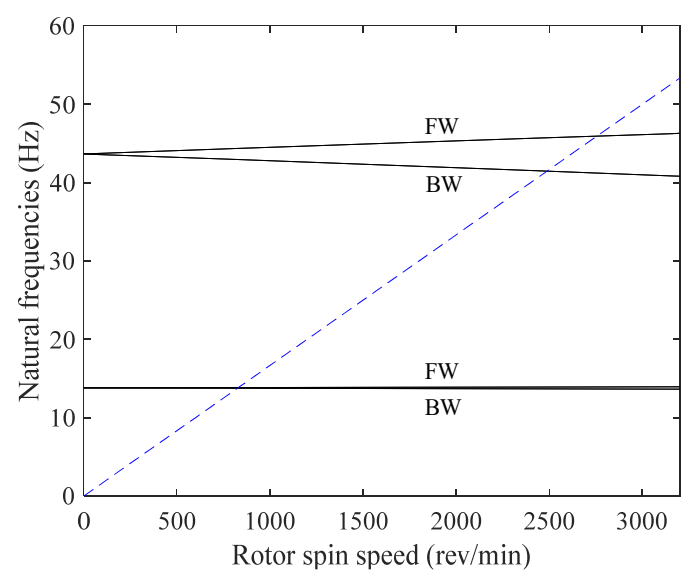

(a) Isotropic stiffness

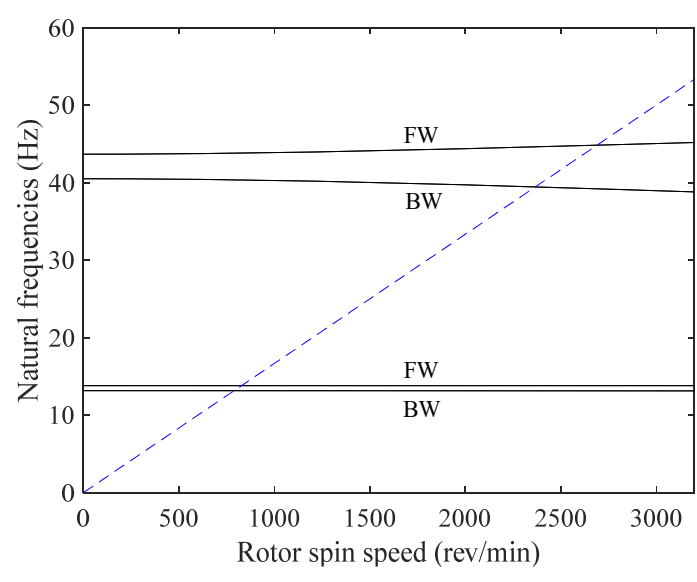

(b) Anisotropic stiffness

Fig. 3 The Campbell diagram of the rotor system with the isotropic and the anisotropic stiffness

As shown in Fig. 3(a), the natural frequencies of forward and backward whirls of the rotor system with isotropic stiffness are equal at $0 \mathrm{r} / \mathrm{min}$ because there is no coupling effect of the gyroscopic moment and the mass and stiffness characteristics of the rotor system are the same along with the lateral directions. For the rotor system with anisotropic supports, the rotor system has different natural frequencies of the forward and the backward whirl at $0 \mathrm{r} / \mathrm{min}$ due to different stiffness characteristics in the lateral directions, as shown in Fig. 3(b). Therefore, the anisotropy of support stiffness makes natural frequency lines of the rotor system tend to diverge from each other.

\subsection{Mode shapes of the rotor system}

The eigenvectors of the state-space matrix at critical speeds are the mode shapes of the rotor system. Figures 4 and 5 show the first two-order backward and forward mode shapes when the damping in bearings is not considered and the support stiffness is isotropic and anisotropic, respectively.

As one can see in Figs. 4 and 5, the whirl directions of the nodes on the rotating shaft are opposite in the backward and forward modes. The first-order backward and forward modes have a $U$ shape where both disks deflect in the same direction. At a further increase in the rotor spin speed, the rotor system traverses the second-order critical speed relating to the second eigenmode with an $\mathrm{S}$ shape where disk 1 deflects towards a direction opposite to that of disk 2 deflects. The whirl orbit of each node is a circle for isotropic stiffness (the whirl orbits look like ellipses due to viewing angles), while the whirl orbits of all nodes are ellipses for the rotor system with stiffness anisotropy. 


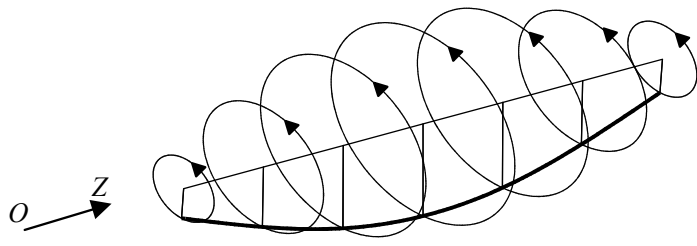

(a) Backward mode (825.1 r/min)

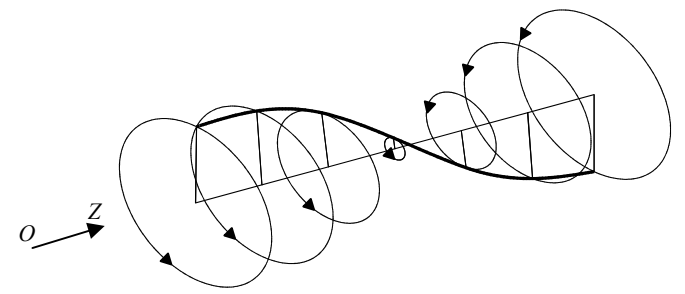

(c) Backward mode (2487.8 r/min)

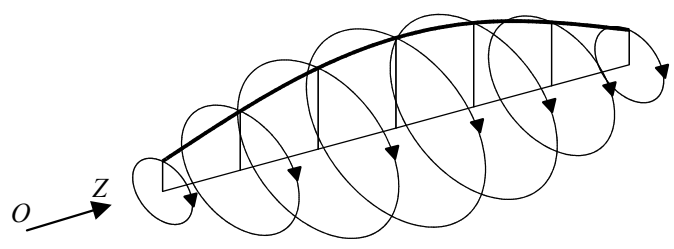

(b) Forward mode (829.9 r/min)

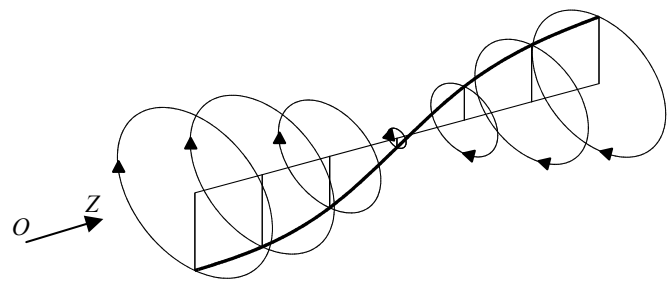

(d) Forward mode (2756.0 r/min)

Fig. 4 Mode shapes of the rotor system with isotropic stiffness

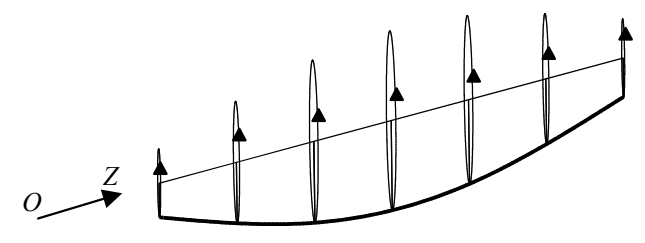

(a) Backward mode (789.2 r/min)

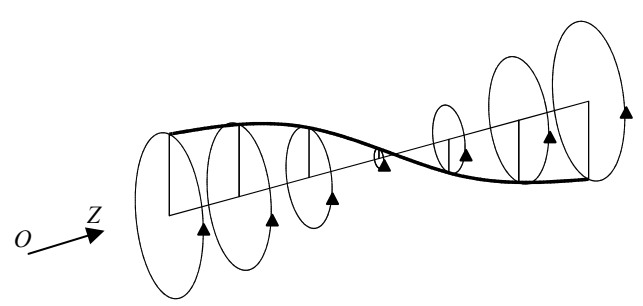

(c) Backward mode (2367.0 r/min)

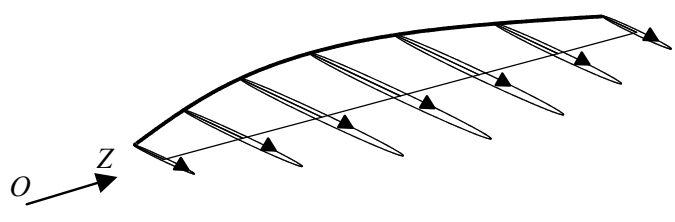

(b) Forward mode (827.6 r/min)

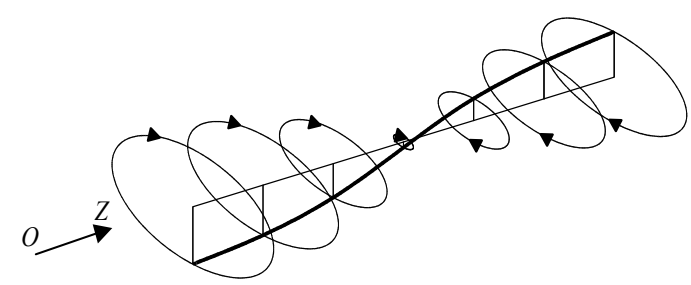

(d) Forward mode (2689.0 r $/ \mathrm{min})$

Fig. 5 Mode shapes of the rotor system with anisotropic stiffness

\subsection{Steady-state unbalance response analysis}

Figure 6(a) shows the amplitude of the steady-state unbalance response when support stiffness is isotropic and there is a $50 \mathrm{~g} \cdot \mathrm{mm}$ unbalance with a zero phase on disk 1 . As shown in Fig. 6(a), there are two very large unbalance response peaks because the bearing damping is not considered in this section. By comparing Fig.6 (a) with Fig. 3(a), it can be seen that the critical speeds are equal to the rotor spin speeds corresponding to the intersections of the rotor spin frequency line and the natural frequency lines of the forward whirl. Therefore, only the forward modes are excited by the unbalance mass for the rotor system with stiffness isotropy.

Figure 6(b) shows the whirl phase of the disks in the $x$-direction, in which the whirl phase in the $y$-direction lags behind that in the $x$-direction by 90 degrees. As shown in Fig. 6(b), the whirl phase of the disks changes by $180^{\circ}$ when the rotor system traverses the critical speeds and there is no damping in the bearings. The whirl phase of disk 2 changes twice, while that of disk 1 changes three times. The unbalance response of disk 1 at a spin speed of $1896 \mathrm{r} / \mathrm{min}$ approximates 0 and the whirl phase of disk 1 also changes by $180^{\circ}$ at the spin speed. This is due to the fact that both disks deflect in the same direction in the first-order forward mode, while disk 1 deflects in the opposite direction to disk 2 in the second-order forward mode. When the 
rotor spin speed gradually increases from the first-order forward critical speed to the secondorder forward critical speed, the relative modal amplitude of disk 1 in the first-order forward mode gradually decreases to zero at first and then increases in the opposite direction to the relative modal amplitude of the second-order forward mode. This process can be verified in Figs. 4(b) and 4(d); thus, the whirl phase of disk 1 changes three times.

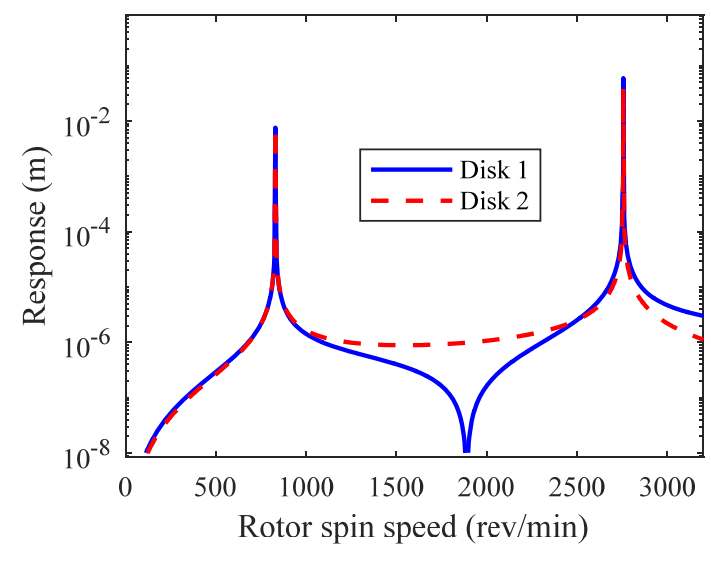

(a) Unbalance response amplitude

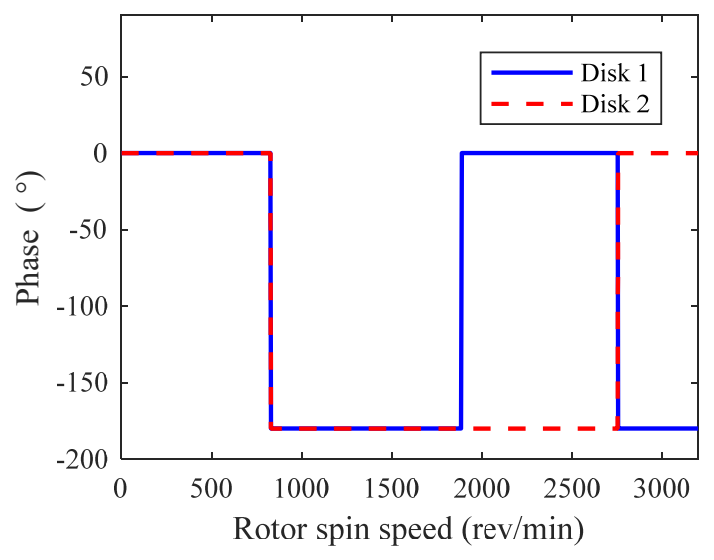

(b) Whirl phase in the $x$-direction

Fig. 6 Unbalance response amplitude and the whirl phase of the disks for isotropic supports

Figure 7 shows the whirl orbits and whirl phase of the disks on the $x-y$ plane when the spin speed of the rotor is $800 \mathrm{r} / \mathrm{min}, 900 \mathrm{r} / \mathrm{min}, 2700 \mathrm{r} / \mathrm{min}$ and $2800 \mathrm{r} / \mathrm{min}$. The cross denotes the start of the orbit and the diamond denotes the end. As shown in Fig. 7, the disks whirl forward in circular orbits and the change of the whirl phase is consistent with that shown in Fig. 6(b).

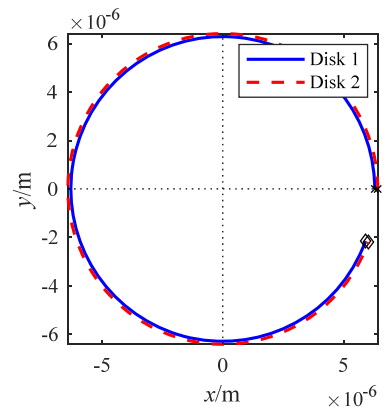

(a) $800 \mathrm{r} / \mathrm{min}$

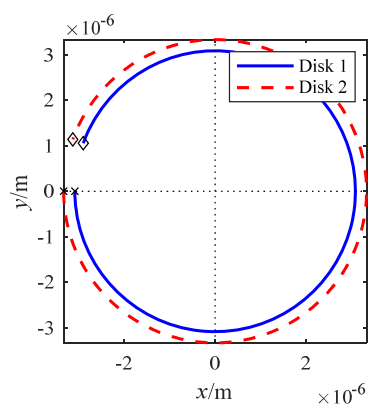

(b) $900 \mathrm{r} / \mathrm{min}$

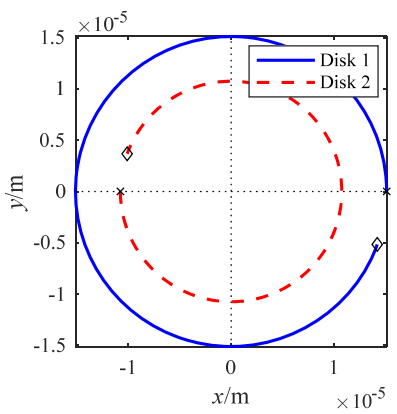

(c) $2700 \mathrm{r} / \mathrm{min}$

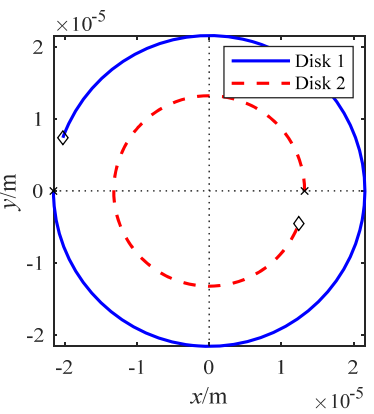

(d) $2800 \mathrm{r} / \mathrm{min}$

Fig. 7 Whirl state of the disks at different spin speeds for isotropic supports

Figures 8-10 show the amplitude of unbalance response and the whirl phase of the disks when the support stiffness is anisotropic. The semi-major axis of an elliptical orbit is taken as the amplitude of unbalance response. To clearly illustrate the whirl state of disk 1 near the first-order backward and forward critical speeds, Fig. 9 shows a partially enlarged view of Fig. 8. The shaded area indicates the spin speed range of backward whirl. As shown in Fig. 3(b), Fig. 8, and Fig. 10, the critical speeds of the rotor system with anisotropic supports are equal to the rotor spin speeds corresponding to the intersections of the spin frequency line and the natural frequency lines of forward and backward whirls. Therefore, the forward and backward modes are excited at this time, and the whirl phase of the disks changes by $180^{\circ}$ at backward and forward critical speeds and the spin speeds corresponding to the zero response.

The bending stress in the rotating shaft is constant when the shaft whirls forward in a circular orbit. This is the case when the rotor on isotropic supports is excited by unbalance. Since the fibres of the rotating shaft are in alternating states of tension and compression 
during the backward whirl, this may lead to high cycle fatigue of the shaft and to rotor instability caused by internal damping of shaft material. As a result, the backward whirl caused by anisotropic supports makes the design of the critical speed and the balancing of the rotor system more complicated.

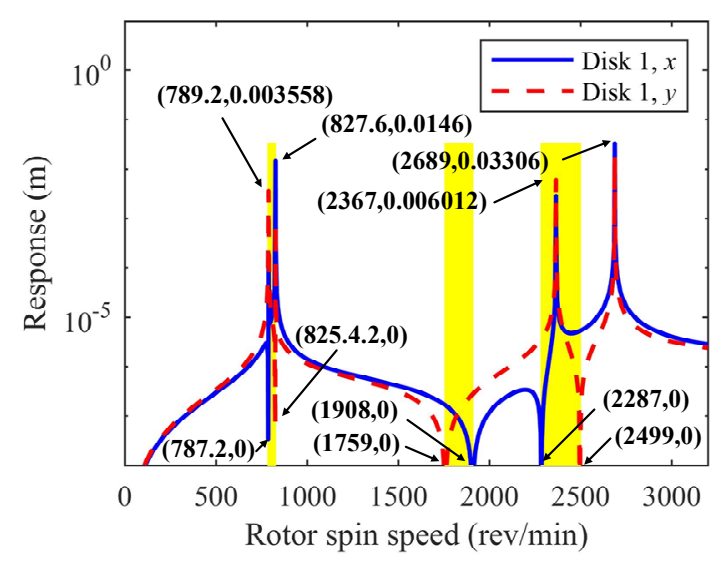

(a) Unbalance response amplitude

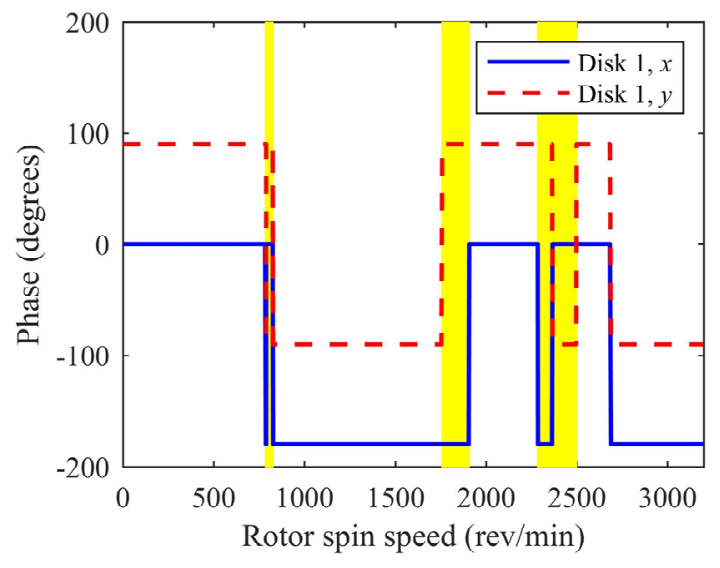

(b) Whirl phase

Fig. 8 The unbalance response amplitude and the whirl phase of disk 1 for anisotropic supports

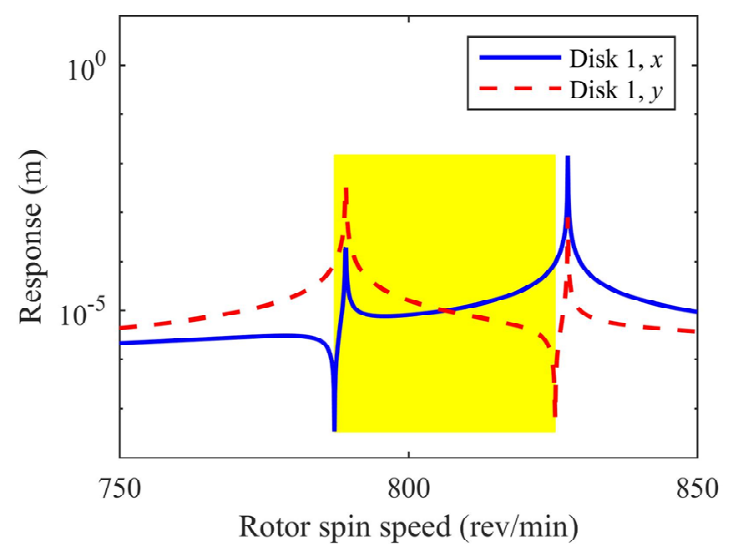

(a) Unbalance response amplitude

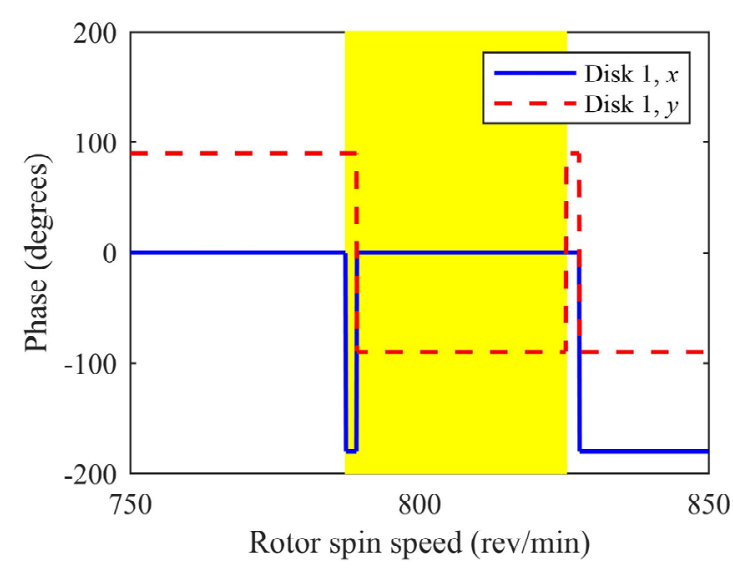

(b) Whirl phase

Fig. 9 A partially enlarged view of Fig. 8

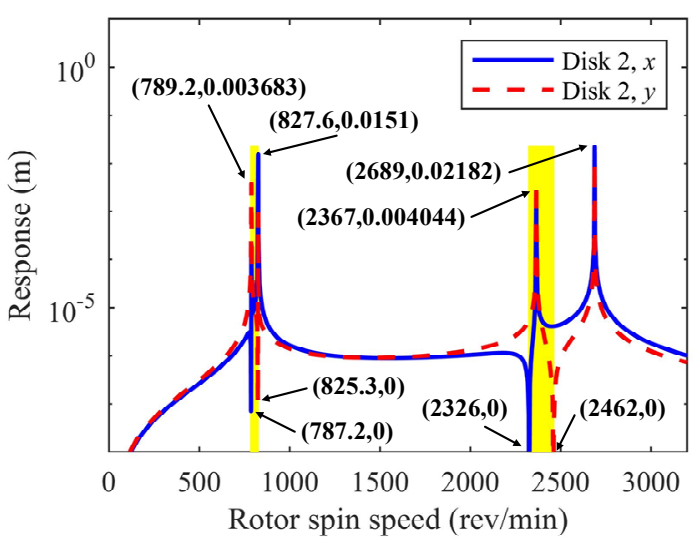

(a) Unbalance response amplitude

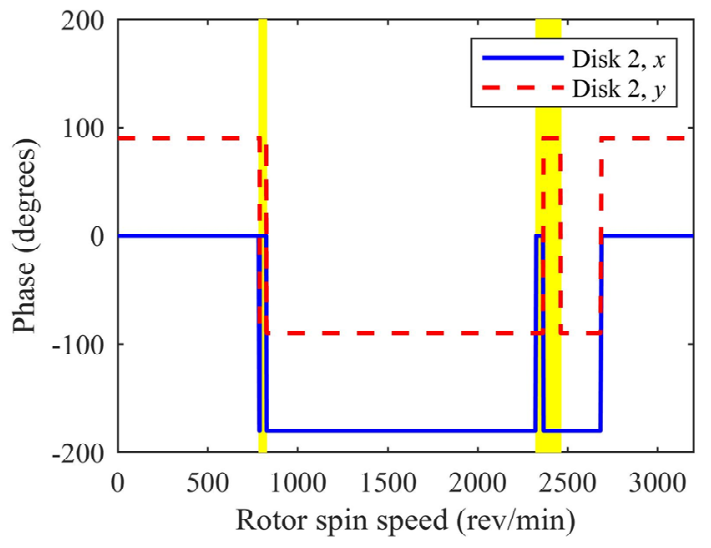

(b) Whirl phase

Fig. 10 The unbalance response amplitude and the whirl phase of disk 2 for anisotropic supports 
Figure 11 shows elliptical whirl orbits and the whirl phase of the disks on the $x-y$ plane when the spin speed is $700 \mathrm{r} / \mathrm{min}, 1000 \mathrm{r} / \mathrm{min}, 1800 \mathrm{r} / \mathrm{min}$, and $2400 \mathrm{r} / \mathrm{min}$. As shown in Fig. 11 , both disks whirl forward at the first two spin speeds, the disk 1 whirls backward and the disk 2 whirls forward at $1800 \mathrm{r} / \mathrm{min}$, and both disks whirl backward at $2400 \mathrm{r} / \mathrm{min}$. Therefore, there may be different whirl directions at different positions of a rotor system with anisotropic support stiffness at a certain spin speed.

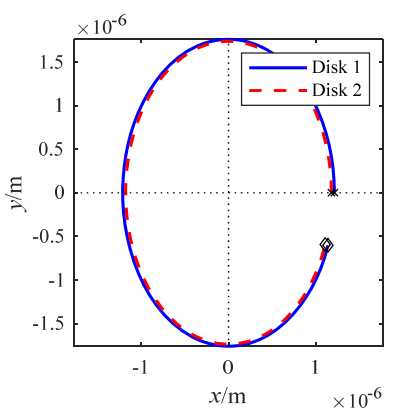

(a) $700 \mathrm{r} / \mathrm{min}$

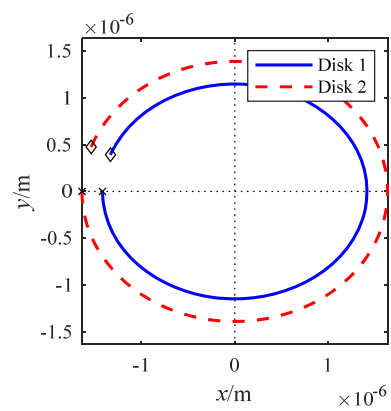

(b) $1000 \mathrm{r} / \mathrm{min}$

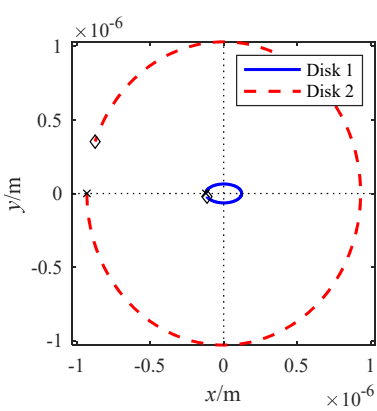

(c) $1800 \mathrm{r} / \mathrm{min}$

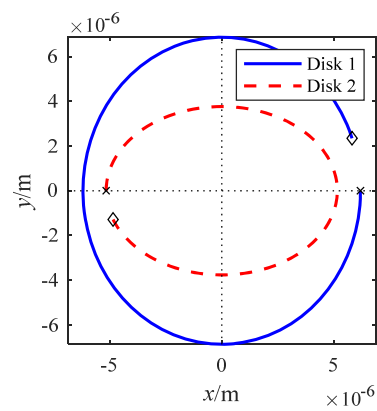

(d) $2400 \mathrm{r} / \mathrm{min}$

Fig. 11 Whirl state of the disks at different spin speeds for anisotropic supports

Figures 6-11 show that under the effect of unbalance force, only the forward whirl with circular orbits is excited in the rotor system with isotropic supports, while the backward whirl and the forward whirl with elliptical orbits occur in the rotor system with anisotropic supports. The above results are consistent with those in Refs. $[5,7,8,14]$, thus verifying the accuracy of the calculation model in this paper.

\subsection{Effect of bearing damping on the steady-state unbalance response}

Section 4.3 does not take into account the damping in bearings. In this section, the direct damping coefficients $c_{x x}$ and $c_{y y}$ are considered and assumed to be equal. Figures 12-15 show the amplitude of unbalance response when different direct damping coefficients are added to the bearings. By comparing the response amplitude in Figs. 12-15 with that in Figs. 8 and 10, it can be seen that the peak values of unbalance response corresponding to the backward and forward critical speeds decrease significantly due to the effect of bearing damping. The backward whirl of the disks in some spin speed ranges is transformed into the forward whirl, and the backward whirl of the disks completely disappears when the bearing damping increases to a certain value. Therefore, the bearing damping not only decreases the amplitude of the forward and backward whirls but also prevents the backward whirl from occurring.

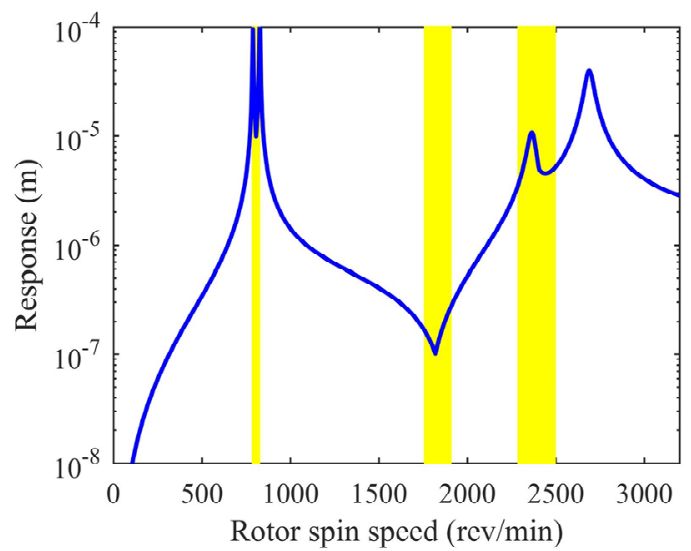

(a) Disk 1

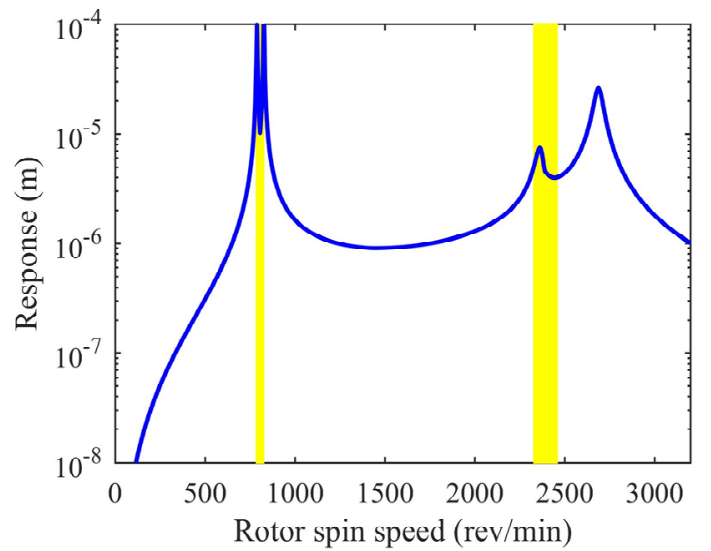

(b) Disk 2

Fig. 12 Damping in bearings: $100 \mathrm{Ns} / \mathrm{m}$ 


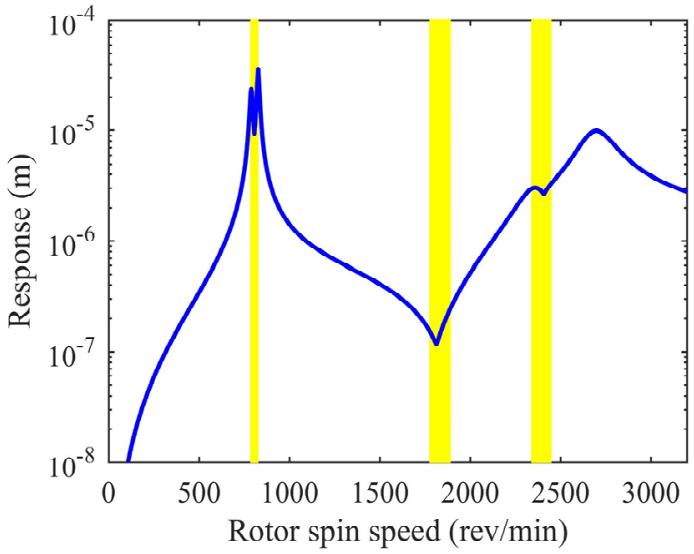

(a) Disk 1

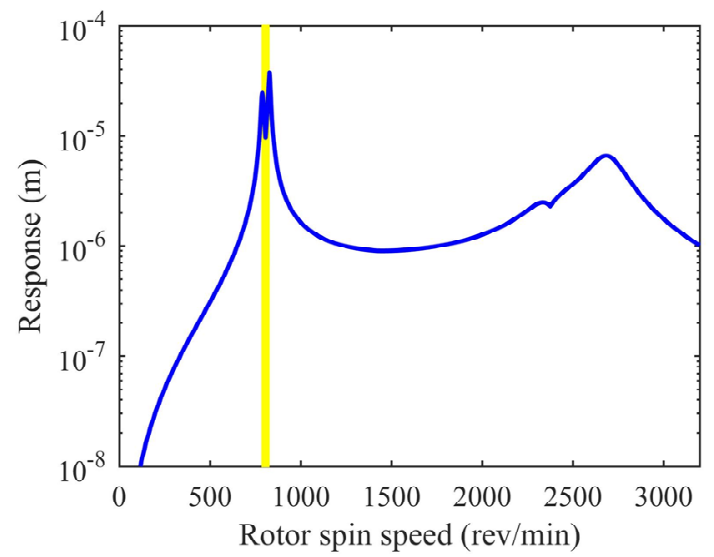

(b) Disk 2

Fig. 13 Damping in bearings: $400 \mathrm{Ns} / \mathrm{m}$

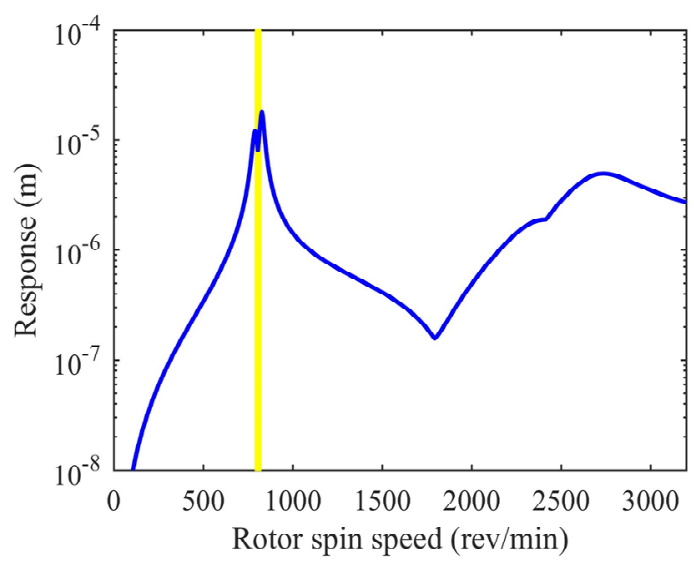

(a) Disk 1

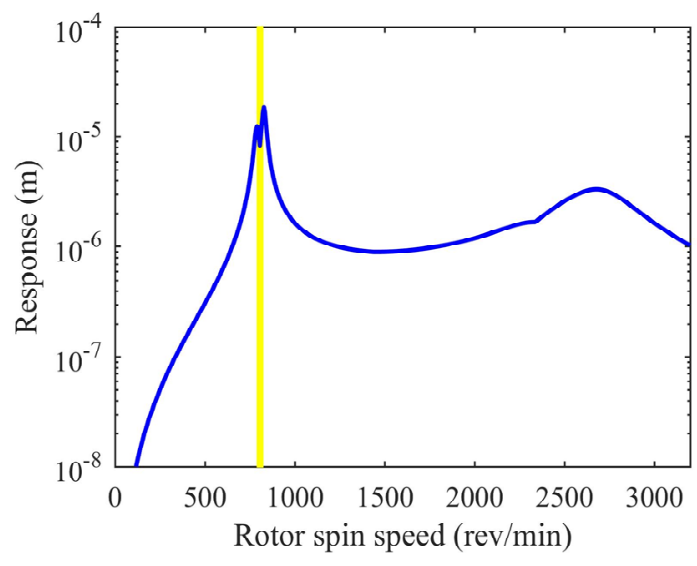

(b) Disk 2

Fig. 14 Damping in bearings: $800 \mathrm{Ns} / \mathrm{m}$

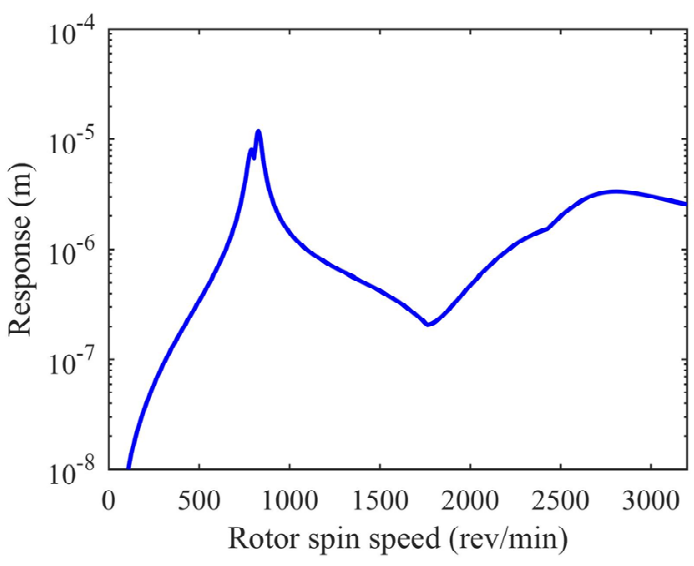

(a) Disk 1

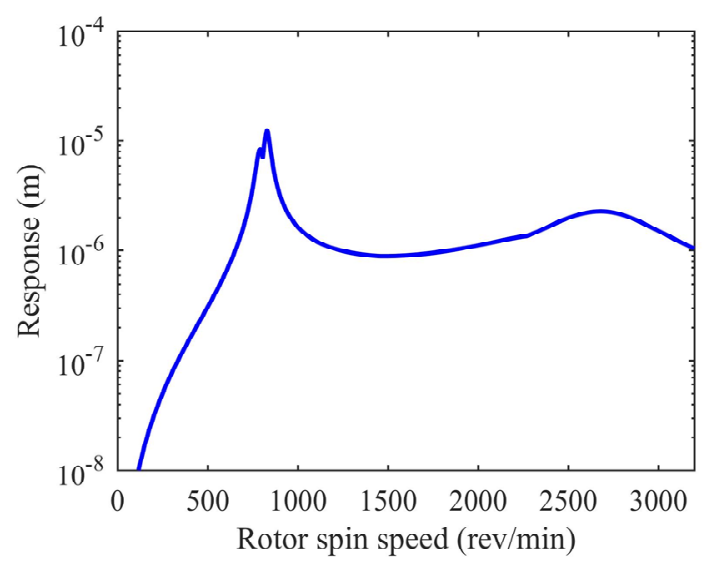

(b) Disk 2

Fig. 15 Damping in bearings: $1200 \mathrm{Ns} / \mathrm{m}$

\subsection{Transient-state unbalance response analysis}

It is assumed that the rotor system starts up from the state of rest and goes through the first-order critical speed with linear laws of rising spin speed. Since Ref. [20] showed that the error of transient-state unbalance response is less than $1 \%$ when the modal reduction method that retains first seven-order modes is employed, the first ten-order modes are retained to 
ensure the calculation accuracy. Ignoring the effects of bearing damping and gyroscopic moment, the maximum natural frequency of the reduced rotor system is $267.91 \mathrm{~Hz}$. The fourth-order Runge-Kutta integration method is used and the time step is chosen to be $0.001 \mathrm{~s}$ in accordance with the sampling theorem.

Figure 16 shows the time domain and frequency domain diagrams of the transient-state unbalance response of disk 2 in the $x$-direction for isotropic supports at the bearing damping of $100 \mathrm{Ns} / \mathrm{m}$ and the run-up acceleration of the rotor system of $0.2 \mathrm{~Hz} / \mathrm{s}$. The unbalance response in the $y$-direction is the same as that in the $x$-direction. By comparing the results in Fig. 6 and Fig. 16, it can be seen that running quickly through the critical speeds of the rotor system decreases the peak value of the unbalance response and only the forward mode is excited at this time.

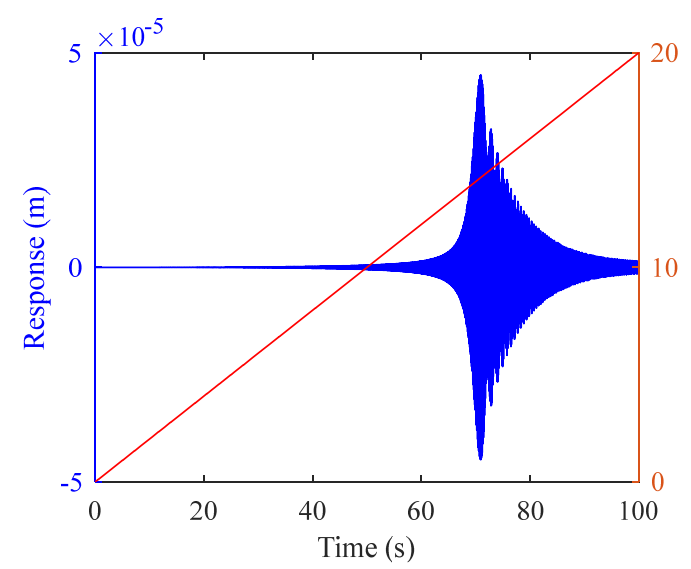

(a) Time domain

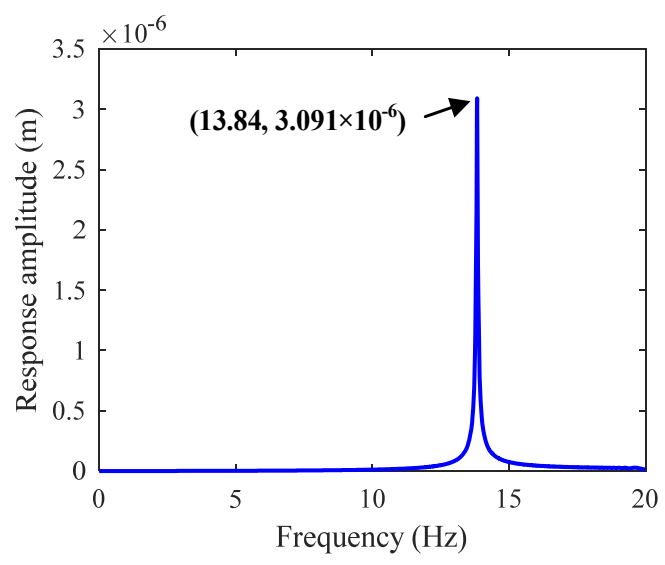

(b) Frequency domain

Fig. 16 Transient-state unbalance response of disk 2 for isotropic supports

Figures 17 and 18 show the time domain and frequency domain diagrams of disk 2 in the $x$ and $y$ directions for anisotropic supports. As illustrated in Figs. 17 and 18, the frequency components of the unbalance response in both directions contain the first-order backward and forward natural frequencies. The first-order forward natural frequency dominates in the unbalance response in the $x$-direction (the strong stiffness axis), while the first-order backward natural frequency dominates in the unbalance response in the $y$-direction (the weak stiffness axis).

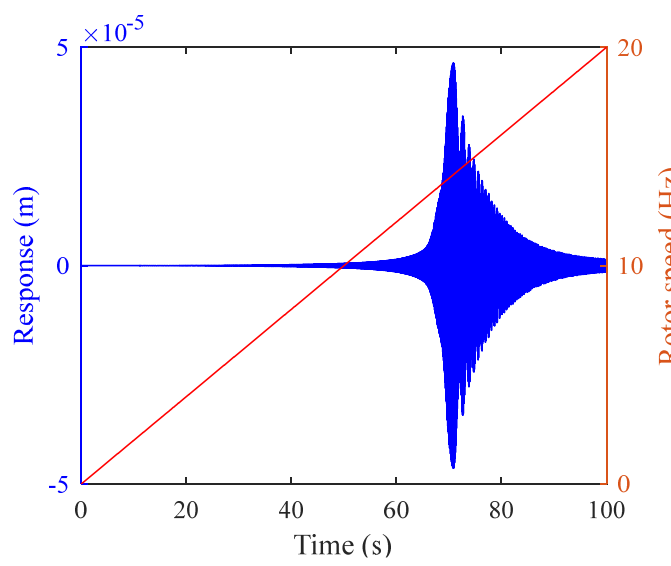

(a) Time domain

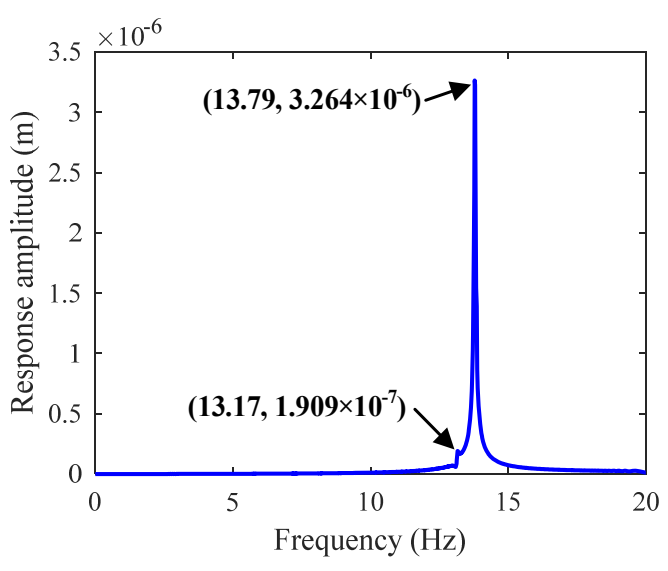

(b) Frequency domain

Fig. 17 Transient-state unbalance response of disk 2 in the $x$-direction for anisotropic supports 


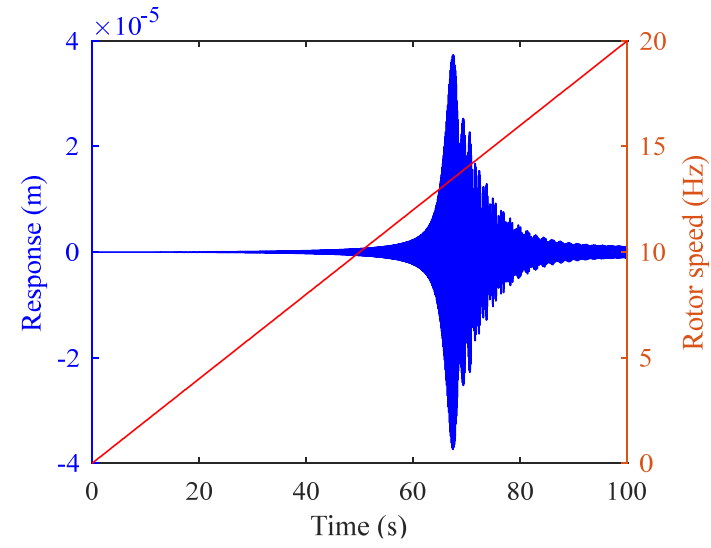

(a) Time domain

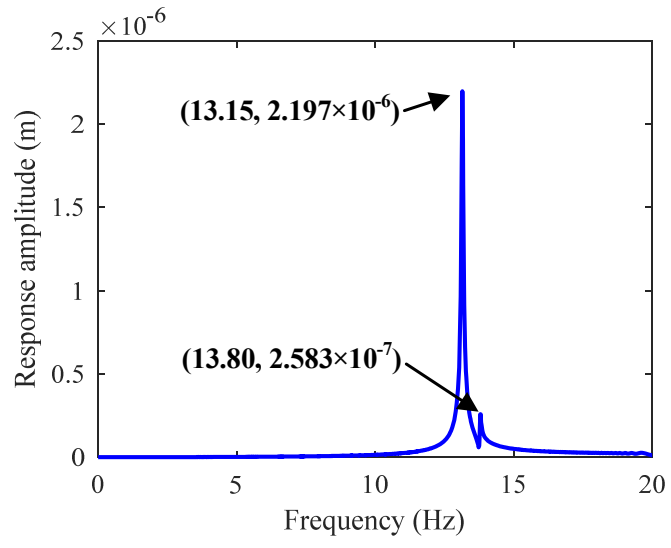

(b) Frequency domain

Fig. 18 Transient-state unbalance response of disk 2 in the $y$-direction for anisotropic supports

As shown in Fig. 10(a), disk 2 whirls backward within the spin speed range 787.3-825.3 r/min (13.12-13.755 Hz). Figure 19(a) shows the whirl orbits of disk 2 within the frequency range 12.96-13.95 Hz when the bearing damping is $100 \mathrm{Ns} / \mathrm{m}$ and the run-up acceleration is $0.2 \mathrm{~Hz} / \mathrm{s}$. As one can see from Fig. 19(a), disk 2 whirls backward within the frequency range 13.12-13.68 Hz, while it whirls forward at other spin frequencies. Furthermore, the whirl orbits of disk 2 approximate straight lines at the spin speeds near the critical point of the backward and forward whirls, while the whirl orbits are ellipses at other spin frequencies.

Figures 19(b-d) show the whirl orbits of disk 2 when the bearing damping is $800 \mathrm{Ns} / \mathrm{m}$, $1200 \mathrm{Ns} / \mathrm{m}$ and $1500 \mathrm{Ns} / \mathrm{m}$, respectively. By comparing the whirl orbits in Fig. 19, it can be seen that the amplitude of the unbalance response and the spin speed range of the backward whirl significantly decrease due to the increased bearing damping. The backward whirl of disk 2 completely disappears when the bearing damping is $1200 \mathrm{Ns} / \mathrm{m}$. The whirl orbits of disk 2 in the frequency range $13.32 \mathrm{~Hz}-13.59 \mathrm{~Hz}$ approximate straight lines, as shown in Fig. 19(c). This is because disk 2 is at the critical point of the backward and forward whirls in the frequency range when the damping in the bearings is $1200 \mathrm{Ns} / \mathrm{m}$. It can be verified in Fig. 19(d) that the whirl orbits of disk 2 in the frequency range are ellipses when the bearing damping is $1500 \mathrm{Ns} / \mathrm{m}$.
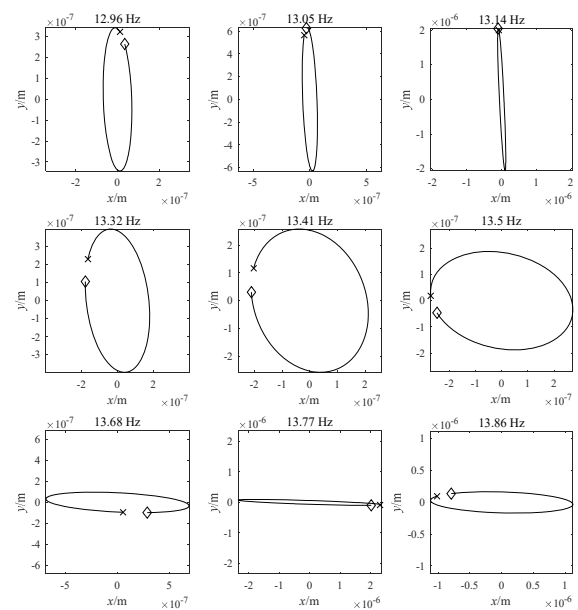

(a) $100 \mathrm{Ns} / \mathrm{m}$
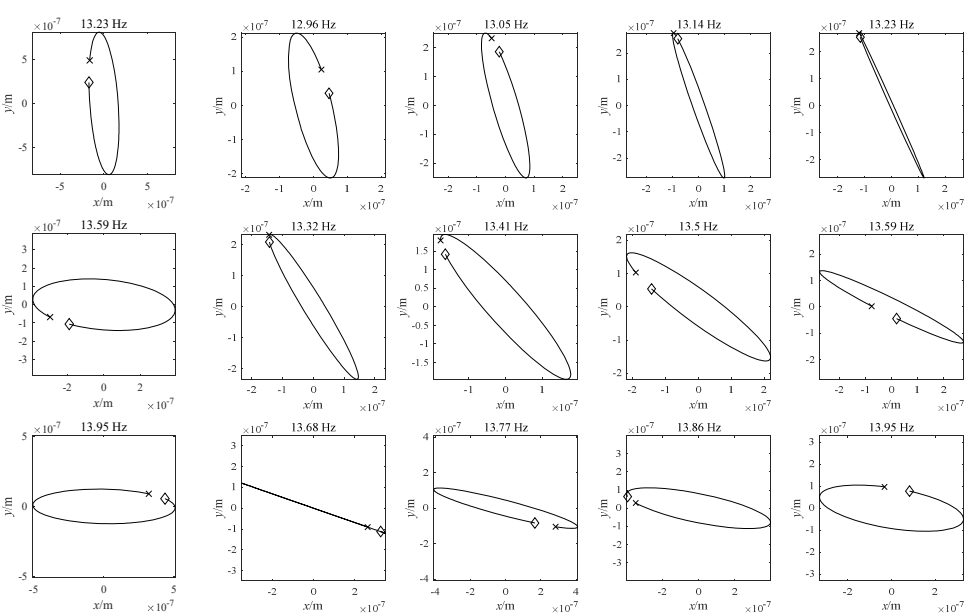

(b) $800 \mathrm{Ns} / \mathrm{m}$ 

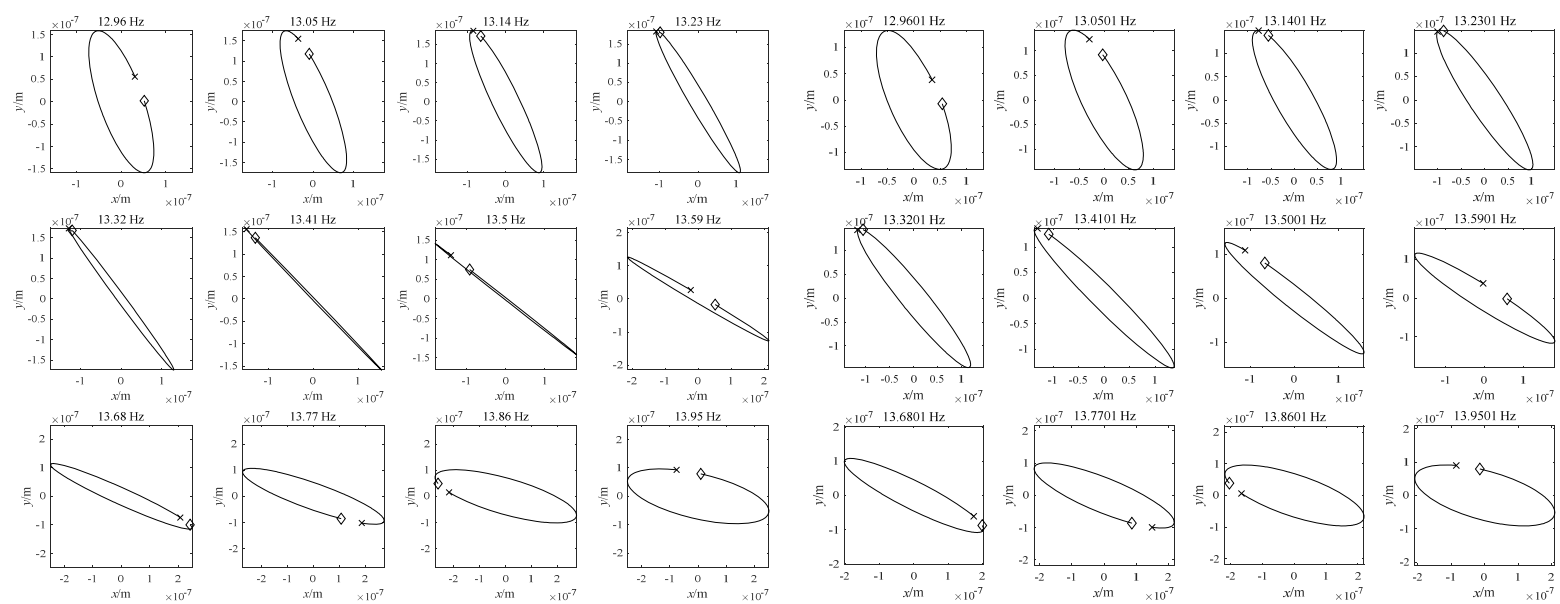

(c) $1200 \mathrm{Ns} / \mathrm{m}$

(d) $1500 \mathrm{Ns} / \mathrm{m}$

Fig. 19 Whirl orbits of disk 2 under the effect of bearing damping of different values

Figure 20 shows whirl orbits of disk 2 when the bearing damping is $100 \mathrm{Ns} / \mathrm{m}$ and the run-up acceleration is $1 \mathrm{~Hz} / \mathrm{s}$ and $3 \mathrm{~Hz} / \mathrm{s}$. The increasing run-up acceleration reduces the amplitude of the forward and backward whirls of the rotor system, thus reducing the magnitude of alternating stress. However, the increasing run-up acceleration cannot reduce the spin speed range of the backward whirl.
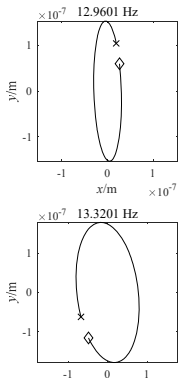

$\begin{array}{ccc}0 & 1 \\ x / \mathrm{m} & \times 10^{7}\end{array}$

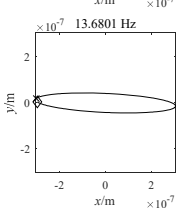

$\begin{array}{ccc}0 & 2 \\ x / m & 2 & -70^{-7}\end{array}$
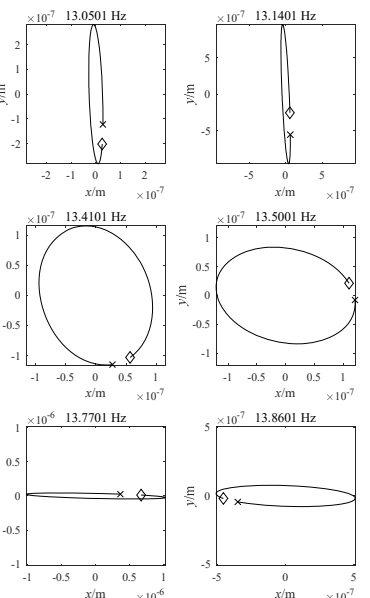

(a) $1 \mathrm{~Hz} / \mathrm{s}$
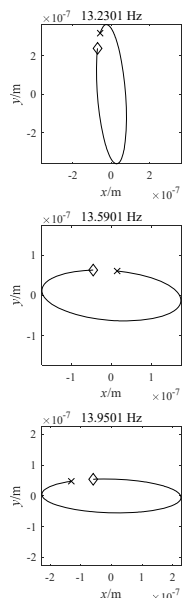

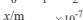
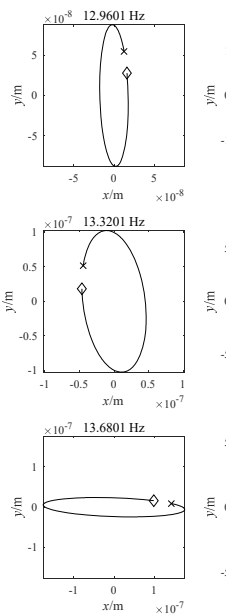

$\underbrace{5}_{5}$
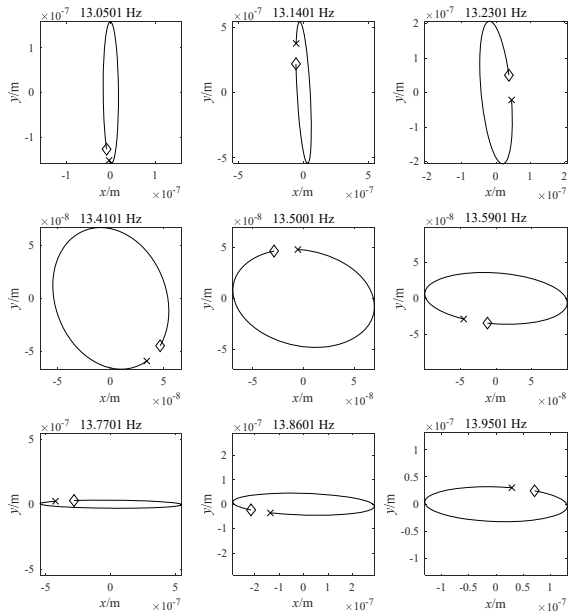

(b) $3 \mathrm{~Hz} / \mathrm{s}$

Fig. 20 Whirl orbits of disk 2 at different run-up acceleration values

\section{Conclusions}

The one-dimensional finite element method is applied to the dynamic modelling of the rotor system with isotropic and anisotropic supports. First, the natural frequencies, whirl state and unbalance response of two types of rotor systems are analysed. Then, the vibration attenuation mechanism of the rotor system with anisotropic supports under the effect of bearing damping and accelerating rotor is discussed in detail. Based on the investigation results, some conclusions are summarized as follows:

(1) The rotor system with anisotropic supports has different natural frequencies for the forward whirl and the backward whirl even at $0 \mathrm{r} / \mathrm{min}$ due to the different stiffness characteristics of the bearing in the lateral directions. Therefore, the stiffness anisotropy makes natural frequency lines of the rotor system tend to diverge from each other. 
(2) The bearing damping not only the amplitude of backward whirl, but also reduces the spin speed range of backward whirl. Therefore, for the rotor system with anisotropic supports, the high cycle fatigue of the shaft and the rotor instability caused by internal damping of shaft material can be alleviated by increasing the bearing damping.

(3) The whirl orbit of the rotor system with anisotropic supports approximates a straight line at the spin speeds near the critical point of the backward whirl and the forward whirl, while the whirl orbits are ellipses at other spin speeds.

(4) For the unbalance response of the rotor system with anisotropic supports, the forward natural frequency dominates in the direction of the strong stiffness axis, while the backward natural frequency dominates in the direction of the weak stiffness axis.

(5) Increasing the run-up acceleration can decrease the amplitude of backward whirl and forward whirl, thus reducing the magnitude of alternating stress. However, this cannot reduce the spin speed range of backward whirl.

\section{Acknowledgements}

A MATLAB toolbox accompanied by the book 'Dynamics of Rotating Machinery' by MI Friswell, JET Penny, SD Garvey \& AW Lees, published by Cambridge University Press, 2010, is used for reference. The authors of this paper would like to thank them.

\section{Nomenclature}

$\begin{array}{ll}u, v & \text { Lateral displacement along the } x \text { and } y \text { axes, } \mathrm{m} \\ \theta_{x}, \theta_{y} & \text { Rotational angle around the } x \text { and } y \text { axes, rad } \\ T & \text { Kinetic energy of the shaft segment, } \mathrm{J} \\ U & \text { Strain energy of the shaft segment, } \mathrm{J} \\ Q & \text { Generalized force, } \mathrm{N} \\ f_{x}, f_{y} & \text { Reaction forces of the bearings in the } x \text { and } y \text { directions, } \mathrm{N} \\ k_{m n} & \text { Stiffness coefficients of the bearing }(m, n=x, y), \mathrm{N} / \mathrm{m} \\ c_{m n} & \text { damping coefficients of the bearing }(m, n=x, y), \mathrm{Ns} / \mathrm{m} \\ \Omega & \text { Rotor spin speed, r/min } \\ N & \text { Number of nodes in the rotor system } \\ t & \text { time, } \mathrm{s} \\ m & \text { Unbalance mass, kg } \\ \varepsilon & \text { Distance between the unbalance mass and the bearing centerline, } \mathrm{m} \\ \delta & \text { Phase of the unbalance mass, rad } \\ j & \text { Imaginary unit } \\ \alpha_{x}, \alpha_{y} & \text { Phase of steady-state unbalance response in the } x \text { and } y \text { directions, rad } \\ \phi(t) & \text { Spin angle, rad } \\ \dot{\phi}(t) & \text { Spin speed, rad/s } \\ \ddot{\phi}(t) & \text { Run-up acceleration, rad/s }\end{array}$

\section{REFERENCES}

[1] Oke, W.A.; Abido, M.A.; Asafa, T.B. Balancing of flexible rotors based on evolutionary algorithms. Mechanics \& Industry 2015, 16(4), 406. https://doi.org/10.1051/meca/2015013

[2] Sun, D.; Li, S.Y.; Zhao, H.; Fei, C.W. Numerical Investigation on Static and Rotor-Dynamic Characteristics of Convergent-Tapered and Divergent-Tapered Hole-Pattern Gas Damper Seals, Materials 2019, 12(14), 2324. https://doi.org/10.3390/ma12142324

[3] Shrivastava, A.; Mohanty, A.R. Identification of unbalance in a rotor system using a joint input-state estimation technique, Journal Sound Vibration 2019, 442, 414-427.

https://doi.org/10.1016/j.jsv.2018.11.019 
[4] Cao, H.R.; Niu, L.K.; Xi, S.T.; Chen X.F. Mechanical model development of rolling bearing-rotor systems: A review, Mechanical Systems and Signal Processing 2018, 102, 37-58. https://doi.org/10.1016/j.ymssp.2017.09.023

[5] Wang, S.; Wang. Y.; Zi Y.Y.; He, Z.J. A 3D finite element-based model order reduction method for parametric resonance and whirling analysis of anisotropic rotor-bearing systems, Journal Sound Vibration 2015, 359, 116-135. https://doi.org/10.1016/j.jsv.2015.08.027

[6] Inagaki, T.; Kanki, H.; Shiraki, K. Response analysis of a general asymmetric rotor-bearing system, ASME Journal of Mechanical Design 1980, 102(1), 147-157. https://doi.org/10.1115/1.3254705

[7] Wettergren, H.L.; Olsson, K.O. Dynamic instability of a rotating asymmetric shaft with internal viscous damping supported in anisotropic bearings, Journal Sound Vibration 1996, 195(1), 75-84. https://doi.org/10.1006/jsvi.1996.0404

[8] Han, D.J. Generalized modal balancing for non-isotropic rotor systems, Mechanical Systems and Signal Processing, 2007, 21(5), 2137-2160. https://doi.org/10.1016/j.ymssp.2006.09.004

[9] Genta, G.; Delprete, C. Acceleration through critical speeds of an anisotropic, nonlinear, torsionally stiff rotor with many degrees of freedom, Journal Sound Vibration 1995, 180(3), 369-386. https://doi.org/10.1006/jsvi.1995.0085

[10] Lee, C.W. Vibration analysis of rotors, Springer Science \& Business Media 1993. https://doi.org/10.1007/978-94-015-8173-8

[11] Joh, C.Y.; Lee, C.W. Use of dFRFs for diagnosis of asymmetric anisotropic properties in rotor-bearing system, ASME Journal of Vibration and Acoustics 1996, 118(1), 64-69. https://doi.org/10.1115/1.2889636

[12] Semenov, S.V.; Nikhamkin, M.S.; Korepanova, O.; Berendorf, Y.A. Experimental investigation of rotor dynamics in aircraft engine with two-axis stiffness anisotropy of supports, 29th Congress of the International Council of the Aeronautical Sciences 2014.

[13] Semenov, S.V.; Nikhamkin, M.S.; Sazhenkov, N.A.; Semenova, I.V. Condition Monitoring of Aircraft Engine Rotor System with Stiffness Anisotropy of Rotor Supports, Comparative Analysis of Accelerometers Mounting Schemes. Advances in Condition Monitoring of Machinery in Non-Stationary Operations 2014. https://doi.org/10.1007/978-3-319-20463-5_35

[14] Zhang, Y.; Mei, X.S., Shao, M.P.; Xu, M.X. An improved holospectrum-based balancing method for rotor systems with anisotropic stiffness, Proceedings of the Institution of Mechanical Engineers Part $C$ Journal of Mechanical Engineering Science 2013, 227(C2), 246-260. https://doi.org/10.1177/0954406212447521

[15] Zorzi, E.S.; Nelson, H.D.; Finite-element simulation of rotor-bearing systems with internal damping, ASME Journal of Engineering for Power 1977, 99(1), 71-76. https://doi.org/10.1115/1.3446254

[16] Zhou, W.J.; Qiu, N.; Wang, L.Q.; Gao, Bo.; Liu Dong. Dynamic analysis of a planar multi-stage centrifugal pump rotor system based on a novel coupled model, Journal of Sound and Vibration 2018, 434, 237-260. https://doi.org/10.1016/j.jsv.2018.07.041

[17] Nelson, H.D.; McVaugh, J.M. Dynamics of rotor-bearing systems using finite-elements, ASME Journal of Engineering for Industry 1976, 98(2), 593-600. https://doi.org/10.1115/1.3438942

[18] Zhou, W.J.; Qiu, N.; Zhang, N., Lai, Z.N.; Gao, B. Research on steady-state characteristics of centrifugal pump rotor system with weak nonlinear stiffness, Transactions of Famena, 2018, 42(3), 87-102. https://doi.org/10.21278/TOF.42306

[19] Friswell, M.I.; Penny, J.E.; Garvey, S.D.; Lees, A.W. Dynamics of rotating machines. Cambridge university press, 2010. https://doi.org/10.1017/CBO9780511780509

[20] Kim Y D, Lee C W. Finite-element analysis of rotor bearing systems using a modal transformation matrix, Journal Sound Vibration, 1986, 111(3), 441-456.

https://doi.org/10.1016/S0022-460X(86)81403-1

\begin{tabular}{|c|c|c|}
\hline Submitted: & 3.4 .2020 & $\begin{array}{l}\text { Shengyuan Li* } \\
\text { Longxi Zheng }\end{array}$ \\
\hline Accepted: & 29.9.2020 & $\begin{array}{l}\text { School of Power and Energy, } \\
\text { Northwestern Polytechnical University, } \\
\text { Xi'an } 710072 \text {, China } \\
\text { *Corresponding author, } \\
\text { lshy@mail.nwpu.edu.cn }\end{array}$ \\
\hline
\end{tabular}

